\title{
Práticas de ensino no estágio supervisionado: o jogo batalha naval como ferramenta de ensino de coordenadas geográficas
}

\section{Supervised training teaching practices: the naval battle game as a geographical coordinate teaching tool}

\section{Prácticas de enseñanza de entrenamiento supervisado: el juego de batalla naval como herramienta de enseñanza coordinada geográfica}

Tatiana Oliveira Santana ${ }^{1}$ http://orcid.org/0000-0002-1352-3420 Tereza Genoveva Nascimento Torezani Fontes ${ }^{2}$ http://orcid.org/0000-0002-6548-9535

\footnotetext{
${ }^{1}$ Graduanda em licenciatura em Geografia- Universidade Estadual de Santa Cruz-UESC-Brasil, tati.2015.fly@ gmail.com

${ }^{2}$ Mestre em Desenvolvimento Regional, Docente do Curso de Geografia- Universidade Estadual de Santa Cruz- UESC-Brasil, terezatorezani@gmail.com
}

\begin{abstract}
Resumo
O ensino e aprendizagem em geografia perpassaram por muitas mudanças no decorrer do espaço-tempo em que se tornou uma ciência, o estudar geografia vem se modificando no ensino básico no decorrer dos anos, tornando-se uma disciplina crítica e construtiva na relação homem-espaço-natureza. Esse trabalho consiste em relatar a experiência de aplicação de atividade lúdica no estágio supervisionado do curso de geografia da Universidade Estadual de Santa Cruz, a respeito de aulas realizadas no período de regência com alunos do $6^{\circ}$ ano do ensino fundamental, na escola municipal do Banco da Vitória Ilhéus-Bahia, no período de abril a junho de 2018, cujo objetivo era vivenciar práticas de ensino na educação básica, mas especificamente com confecção e realização de jogos didáticos.
\end{abstract}

Palavras-chave: Jogos didáticos. Cartografia. Ensino de Geografia.

\begin{abstract}
Teaching and learning in geography has undergone many changes over the space-time that it became a science, studying geography has been changing in basic education over the years, becoming a critical and constructive discipline in the relationship between man-space-nature. This paper reports on the experience of applying recreational activities in the supervised internship of the geography course of Santa Cruz State University, regarding classes conducted during the period of conduct with students of the 6th grade of elementary school, at the municipal school of the Bank. Vitória-Ilhéus-Bahia, from April to June 2018, whose objective was to experience teaching practices in basic education, but specifically with the making and conducting of didactic games.
\end{abstract}

Keywords: Didactic games. Cartography. Geography teaching.

\section{Resumen}


La enseñanza y el aprendizaje en geografía han sufrido muchos cambios en el espacio-tiempo que se convirtió en una ciencia, el estudio de la geografía ha ido cambiando en la educación básica a lo largo de los años, convirtiéndose en una disciplina crítica y constructiva en la relación entre el hombre y el espacio. naturaleza. Este documento informa sobre la experiencia de aplicar actividades recreativas en la pasantía supervisada del curso de geografía de la Universidad Estatal de Santa Cruz, con respecto a las clases realizadas durante el período de conducta con estudiantes de 6to grado de la escuela primaria, en la escuela municipal del Banco. Vitória-Ilhéus-Bahia, de abril a junio de 2018, cuyo objetivo era experimentar prácticas docentes en educación básica, pero específicamente con la realización y realización de juegos didácticos.

Palabras clave: Juegos didácticos. Cartografía. Enseñanza de geografía.

Recebido em: 26/11/2019

Aceito para publicação em: 28/12/2019

\section{Introdução}

A busca por se tornar um profissional de excelência é sempre contínua no que diz respeito a ser um professor, o processo de formação de um docente é árdua e continuada, no decorrer de sua carreira o estágio supervisionado é o início de uma caminhada chamada docência, portanto tem suma importância na formação de um profissional na área da educação. A realidade no âmbito profissional exige pessoas capacitadas e dispostas a levar o papel de professor a outro patamar, o estagio supervisionado é uma das possibilidades de compreender e se comprometer com o ensino, que vai além de apenas ensinar

Com isso a ida ao ambiente escolar para observar e analisar as formas e maneiras de ensinar com a ajuda do estágio supervisionado propõe aos discentes dos cursos de licenciatura uma noção real do ambiente e a confirmação da sua carreira na educação.

O ensino de geografia vem mudando durante os anos, professores cada vez mais jovens e a revolução tecnológica ainda mais presente no ambiente escolar, deste modo, o ensino aprendizagem requer uma atenção maior, em um mundo onde a informação está a todo vapor. $\mathrm{O}$ ensino perpassa pela concentração de informações e é necessário que o aluno tenha condições de absorver essa informação de forma satisfatória e construtiva, para que seja possível sua interação com o meio.

De acordo com Passini (2010): 
A aula é como um jogo em que os participantes vão trabalhar para atingir uma meta: a aprendizagem significativa, que tanto professores como alunos devem almejar. O professor, como líder, precisa fazer um jogo de sedução e convencimento para que todos se sintam envolvidos e suficientemente comprometidos com o alvo a ser alcançado. O plano conhecido e decidido com os participantes tem, muitas vezes, caráter de uma negociação em relação ao alvo, ao cronograma, à sequência das etapas e às formas de avaliação (PASSINI, 2010 p.151).

O estágio supervisionado tem se caracterizado como um meio dos discentes, em cursos de licenciatura, construir sua identidade e por em pratica as tantas teorias que vêem no decorrer da sua formação. Nesse período o objetivo do futuro docente é perceber quais as dificuldades que a educação perpassa dar contribuições em metodologias e vivenciar o ambiente escolar. Como afirma Penin 2009, "a cultura profissional da área do ensino contém conhecimentos sistematizados que estão presentes na formação inicial e são reiterados nos diferentes momentos de formação continuada."

Nessa perspectiva o estágio supervisionado auxilia diretamente na primeira formação do docente, o mantendo próximo ao ambiente escolar, com os alunos e as realidades em que estão inseridos e com as diversidades e problemas dessa profissão.

Um dos pontos que podem ser analisados no estágio supervisionado, no caso do curso de geografia, é a necessidade de fazer com que os alunos compreendam a importância de se estudar a geografia no ensino seja ele fundamental ou médio, e como ela pode auxiliar no desenvolvimento do mesmo como cidadão. $\mathrm{O}$ estagiário enquanto pesquisador neste momento pode auxiliar em métodos que instiguem os alunos a esse entendimento.

Com ressalta Bu e Melo:

A pesquisa torna-se fundamental para que os estagiários, juntamente com os professores efetivos e o professor orientador, busquem métodos capazes de evitar que as aulas de Geografia sejam apenas aulas burocráticas, incapazes de atrair a atenção dos alunos para a importância da disciplina de Geografia em suas vidas (BU; MELO, 2014, p.02) 
Sendo assim, o estágio age não apenas como forma de conclusão de um curso, mas sim como meio de construir sua identidade quanto professor de pessoas que precisam entender a importância de serem atuantes e decisivos sobre situações que o envolvem, seja ela em escala maior ou menor.

A forma como um professor trabalha e desenvolve os conteúdos que devem ser tratados em sala de aula influencia diretamente no grau de compreensão e assimilação dos alunos, desta forma, procurar criar metodologias mais acessíveis a realidade do aluno é um dos principais pontos do estagio.

Desta forma as atividades lúdicas são uma opção viável e talvez mais construtiva. De acordo com Rupel (2011, pag. 2) "Muitas vezes durante o desenvolvimento dos conteúdos de Geografia no cotidiano da sala de aula, as atividades tornam-se cansativas e pouco atrativas para os alunos, principalmente porque nem sempre se buscam metodologias alternativas para motivá-los."

Sendo assim o uso de atividades lúdicas que envolvam jogos e participação ativa do aluno, os instigam e os trazem de forma mais significativa para a realização da atividade, de certa forma contribuindo no seu desenvolvimento perante o conteúdo a ser trabalhado como afirma Rupel (2011, pág.5), “Ao participar de atividades lúdicas o educando desenvolve a imaginação, pratica a interação e a integração com os colegas e essas ações favorecem uma aprendizagem de qualidade em todas as áreas do conhecimento."

E é nesse contexto que o uso do jogo batalha naval se aplica nesta pesquisa, adaptado para trabalhar coordenadas geográficas e também ajudar a compreender alguns outros conceitos geográficos que talvez só na teoria não tivesse um bom desempenho no processo de ensino aprendizagem dos alunos. Ainda sobre isso Rupel (2011, pág. 8) coloca que "Com objetivos bem definidos, os jogos se constituem um apoio didático podem ser trabalhados e aplicados para a aprendizagem e construção de conceitos geográficos."

A aplicabilidade de atividades lúdicas e a utilização de jogos no ensino de geografia possibilitam uma aprendizagem significativa para o aluno, ajuda no processo de interação, socialização e relacionamentos em sala, alem de pode ser trabalhado vários conceitos geográficos, nessa perspectiva o jogo aparece como uma ferramenta importante. 


\section{Batalha naval como ferramenta de ensino de geografia}

A escola analisada foi a Escola Municipal do Banco do Vitória (EMBEV), localizada no bairro Banco da Vitoria no município de ilhéus-BA, a mesma é dividida em dois espaços, um é a sede e o outro um anexo, na primeira esta presente toda organização administrativa, a secretaria, biblioteca e laboratório. No anexo encontra-se uma área de lazer mais ampla com árvores e uma quadra de área improvisada pela própria comunidade escolar.

A classe observada foi o $6^{\circ}$ ano, turma $\mathrm{F}$, do turno vespertino, foi de observado apenas duas aulas, uma sobre a Pangeia e a outra sobre a formação dos continentes e a composição da Terra. A turma era composta por 15 alunos mantinham uma ótima relação com a professora regente, possuíam entre 10 e 12 anos de idade, todos moram no Banco da Vitória, a maioria da sala eram meninas.

A realização deste trabalho partiu do período de regência do estágio supervisionado obrigatório com os alunos do $6^{\circ}$ ano $\mathrm{F}$ do ensino fundamental II, da Escola Municipal do banco da Vitória, na cidade de Ilhéus-Ba. Dentre os assuntos e atividades trabalhadas na tua durante a regência, coordenadas geográficas foi um deles, e para trabalhar esse conteúdo de forma teórico-prática foi utilizado o jogo batalha naval como ferramenta de ensino.

Essa atividade foi dividida em três etapas, a primeira etapa consistiu em uma aula expositiva, para que os alunos conseguissem compreender a atividade, era necessário que compreendesse o conteúdo, por tanto a aula expositiva e exercícios no caderno foram essenciais para o processo de compreensão.

No segundo momento foi apresentado o jogo batalha naval, como funciona, quais são as regras e como ele seria adaptado e modificado para trabalhar coordenadas geográficas, nesse momento os próprios alunos confeccionaram o jogo, usando uma cartolina eles reproduziram um planisfério, claro que aulas anteriores havíamos discutido outros assuntos que são necessários para confecção do jogo, como localização, orientação, hemisférios, paralelos e meridianos. Para se discutir paralelos e meridianos utilizamos um pequeno mapa mundo (foto 1) em outra atividade, e no caderno eles encontraram o paralelo e meridiano principal que seriam necessários na atividade seguinte. 
Foto 1- Mapa mundi para discussão sobre paralelos e meridianos.

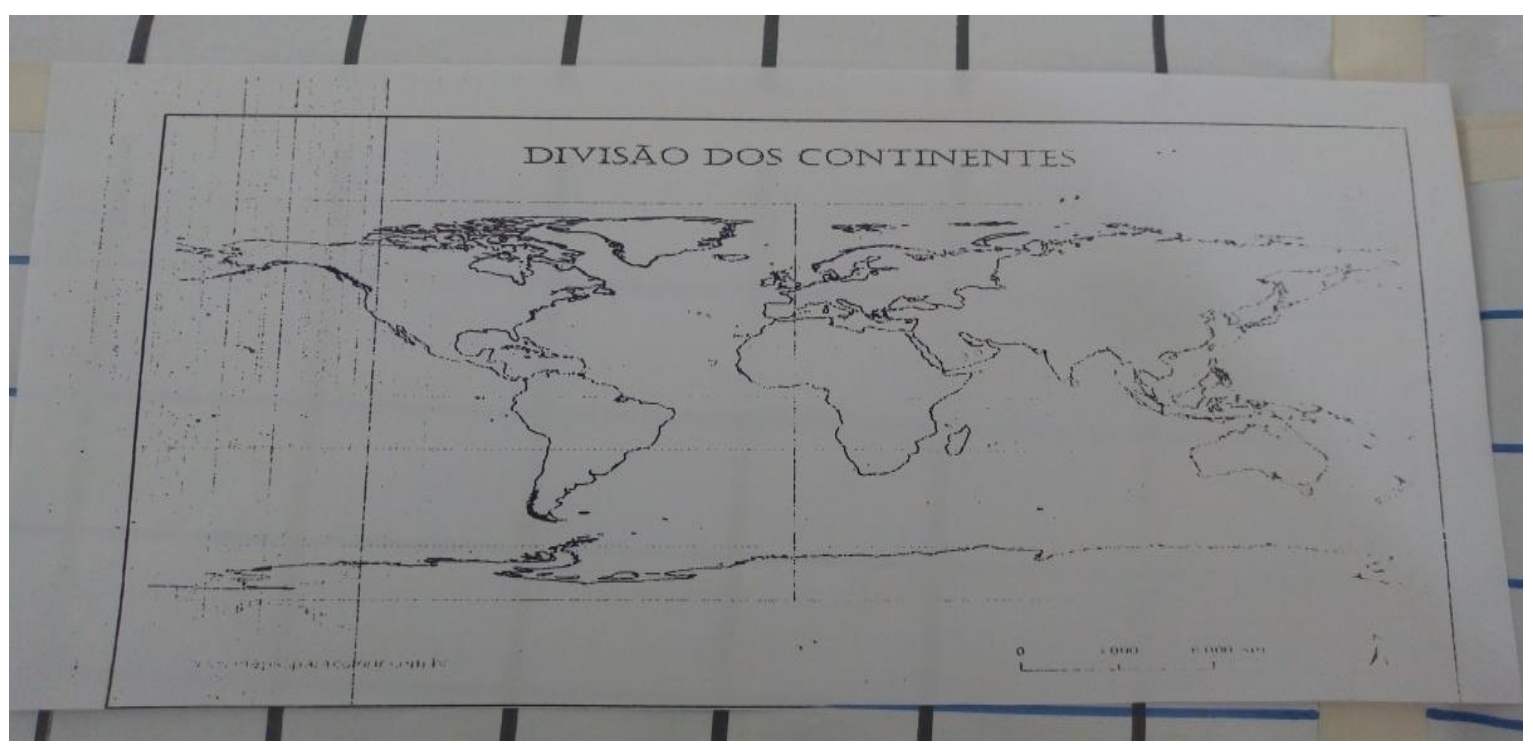

Fonte: Dados da pesquisa. Foto Tatiana Oliveira Santana (2018).

No terceiro momento partimos para a aplicação do jogo, onde a sala foi dividida em dois grandes grupos, cada grupo ficou com seu planisfério (fotos 2 e 3) e colocaram navios (pequenos pontos verdes de EVA) em determinadas coordenadas, sem que o grupo oponente visse. Cada grupo tinha direito a um ataque por vez, e todos os ataques deveriam ser registrados para que não repetissem a mesma coordenada, o intuito era derrubar os navios do grupo oponente, o grupo que naufragasse mais navios venceria.

Foto 2 - Base para o jogo batalha naval.
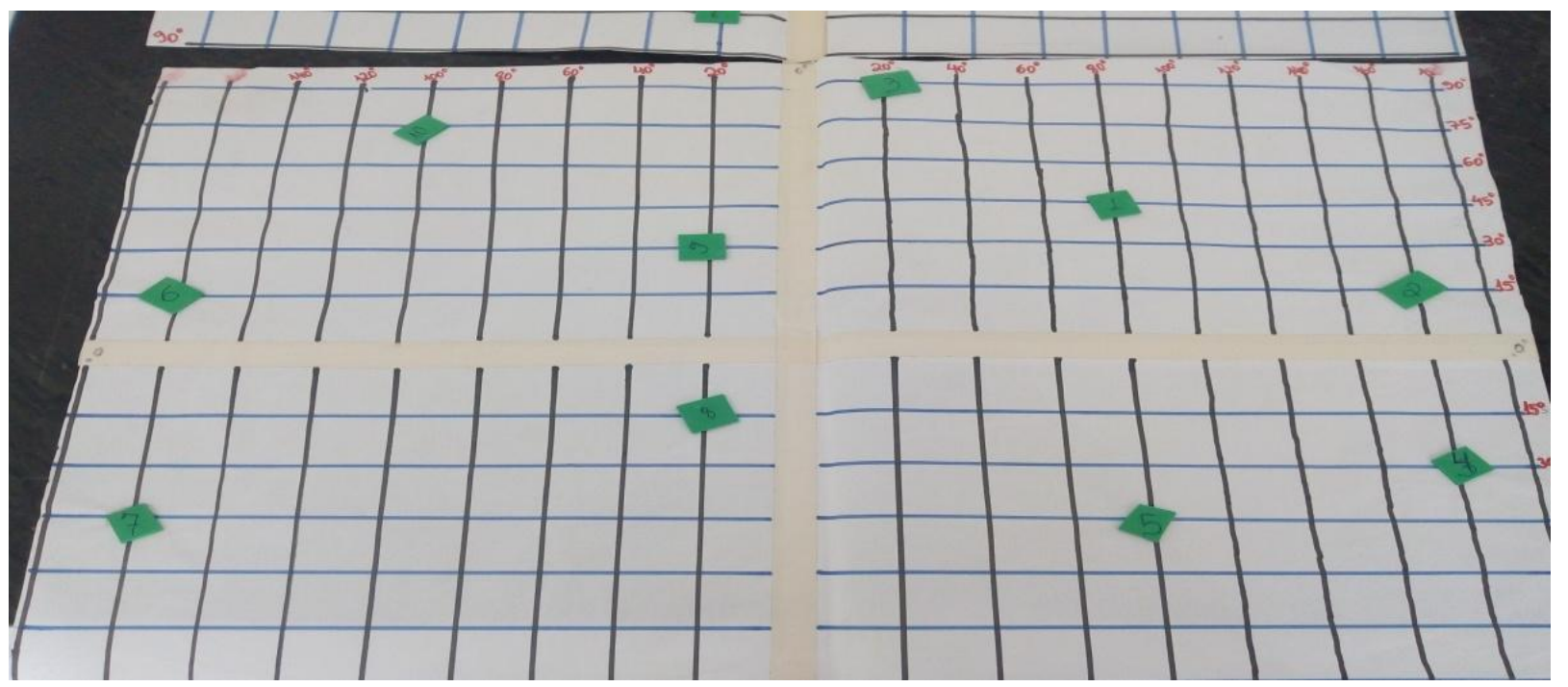

Fonte: Dados da pesquisa, Foto Tatiana Oliveira Santana (2018). 
Cada grupo tinha direito a um ataque por vez, e todos os ataques deveriam ser registrados para que não repetissem a mesma coordenada, o intuito era derrubar os navios do grupo oponente, o grupo que naufragasse mais navios venceria.

Foto 3 - Os grupos formados pelos alunos

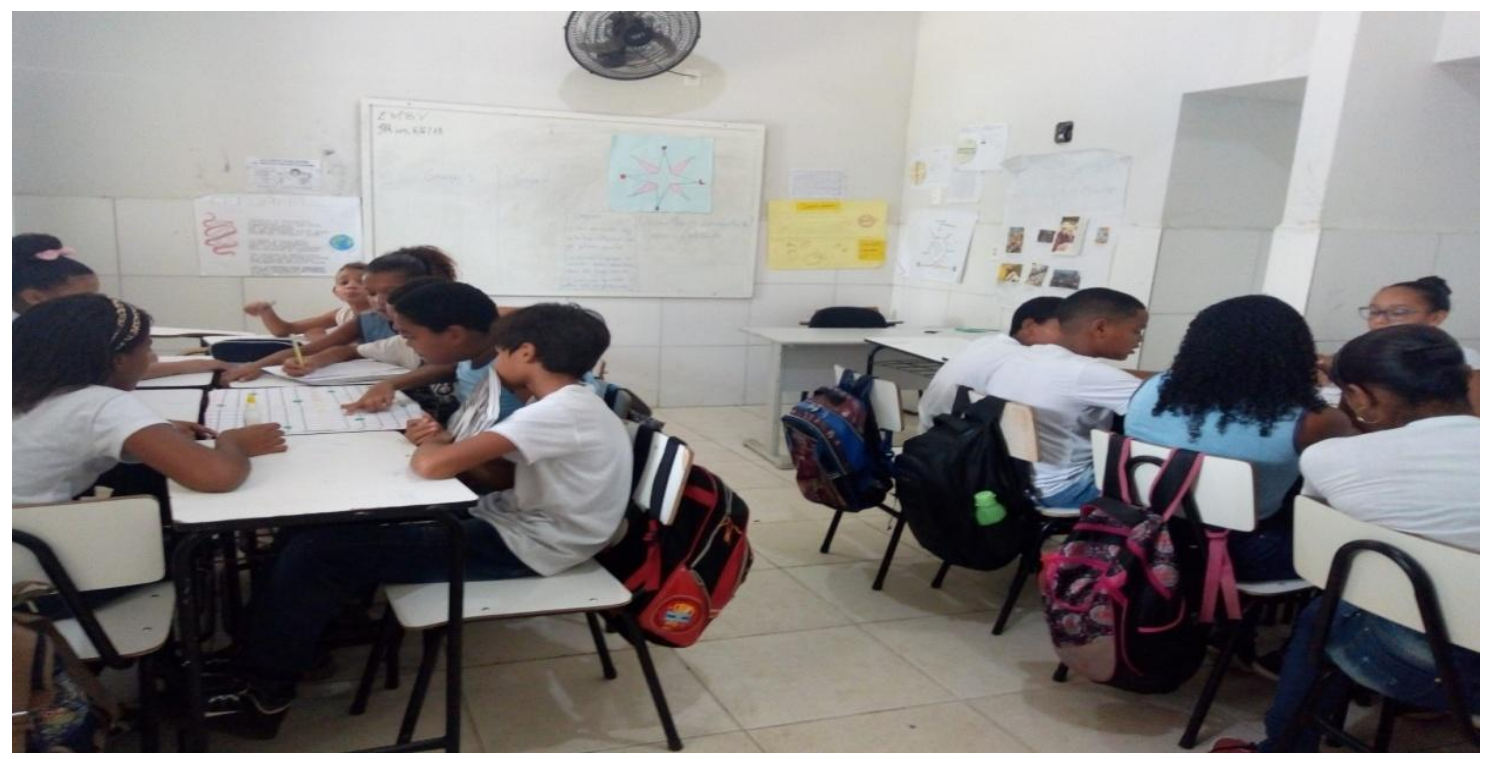

Fonte: Dados da pesquisa, Foto Tatiana Oliveira Santana (2018).

Com o auxilio dessa atividade foi possível fazer com que os alunos compreendessem de forma mais pratica todos os exercícios feitos em sala de aula e todas aos apontamentos feitos no caderno, fazendo com que assim os alunos assimilassem totalmente o assunto e suas funcionalidades. Com ajuda desta atividade foi possível trabalhar diversos conceitos da geografia como coloca Rupel:

Podemos também explorar através de atividades lúdicas os conceitos: "localização" que permite localizar/situar os acontecimentos; o de "orientação" que encaminha à localização no espaço, dos eventos, dos lugares em si; o de "representação" que é a forma de abstrair da realidade concreta e expressá-la mental ou graficamente (RUPEL 2011, p. 9)

Nesse sentido essa atividade além de auxiliar no processo de aprendizagem nesse conteúdo, que é as coordenadas geográficas, ela também pode abarcar outros conteúdos vistos anteriormente, desta forma essa atividade teve suma importância no processo de assimilação também de outros assuntos que estão associados a este como, 
orientação, pois era necessário que os alunos soubessem os pontos cardeais, rosa dos ventos, que entendessem o que era latitude e longitude, desta forma além de seu papel prático dentro do conteúdo proposto, ela também ajudou a fixar outros assuntos vistos em outros momentos.

\section{Considerações finais}

O estágio supervisionado tem propiciado a evolução profissional dos licenciados já mesmo na academia, pois são esses momentos em sala de aula que possibilita aprender e aperfeiçoar seus conhecimentos e experiências quando entra em contato com a educação. Deste modo o estágio supervisionado em ensino de geografia possibilita aos graduandos um convívio direto com a sala de aula, para que posso compreender o papel do professor de geografia na sociedade.

O ensinar geografia demanda estudo e compreensão de que estamos formando cidadãos que precisam compreender o mundo, e as relações que o cercam, a fim de entender todo o processo social em que está inserido.

O uso de atividades práticas e lúdicas ajuda o aluno no processo de apreensão de determinados conteúdos, e o professor como educador precisa recorrer a outras metodologias que possam suprir dificuldades de aprendizagem em modos tradicionais. Nesse sentido o uso de jogos didáticos, ou jogos adaptados para ensinar determinados conteúdos, auxiliam no processo de ensino aprendizagem e de certa forma aproxima aí dá mais o professor do aluno. Sendo assim, esse trabalho buscou aplicar uma metodologia utilizando o jogo batalha naval como base para compreensão de coordenadas geográficas.

\section{Referências}

BU, José Cícero; MELO, Josandra Araujo Barreto de. Estagio supervisionado e (re) construção das metodologias no ensino-aprendizagem de geografia. VII congresso brasileiro de geógrafos, Anais... Vitória-ES, 12 p. ago/2014.

PASSINI, Elza Yasuko; PASSINI, Romão; MALYSZ, Sandra T. Prática de ensino de geografia e estágio supervisionado. 2. ed. São Paulo: Contexto, 2010. 
PENIN, Sonia. Profissão docente e contemporaneidade. In: PENIN, S.; MARTINEZ, M.; ARANTES, V. A. Profissão docente: pontos e contrapontos. São Paulo: Sumnus, 2009.

RUPEL, Maria Aparecida Pavelski. Atividades lúdicas: proposições metodológicas para o ensino de geografia escolar.dia a dia da educação, Curitiba, Sec/selepar, 2011. Disponível em: http://www.diaadiaeducacao.pr.gov.br/portals/pde/arquivos/1634-8.pdf . Acesso em: 04 de agosto. 2019. 